\title{
Sunspots sketches during the solar eclipses of 9th January and 29th December of 1777 in Mexico
}

\author{
Fernando Domínguez-Castro ${ }^{1}$, María Cruz Gallego ${ }^{2,3}$, and José Manuel Vaquero ${ }^{2,3, *}$ \\ 1 Instituto Pirenaico de Ecología, Consejo Superior de Investigaciones Científicas (IPE-CSIC), Zaragoza 50059, Spain \\ 2 Departamento de Física, Universidad de Extremadura, Badajoz 06006, Spain \\ 3 Instituto Universitario de Investigación del Agua, Cambio Climático y Sostenibilidad (IACYS), Universidad de Extremadura, \\ Badajoz 06006, Spain \\ ${ }^{*}$ Corresponding author: jvaquero@unex.es
}

Received 31 March 2017 / Accepted 9 May 2017

\section{ABSTRACT}

\begin{abstract}
Two sunspot observations recorded by the Mexican Felipe de Zúñiga y Ontiveros have been revealed from a manuscript. One sunspot group was recorded on 9th January 1777 and four sunspot groups on 29th December 1777. Both records were taken during the observation of solar eclipses from Mexico City and their description also included sketches of the solar disk with sunspots. The sunspot group corresponding to 9th January was also observed by Erasmus Lievog. The observation on 29th December 1777 is the only record corresponding to this date.
\end{abstract}

Key words. Historical records - Sunspot - Solar activity - Sun - Solar cycle

\section{Introduction}

Sunspot counting is the longest-running experiment in the world (Owens 2013) and the base of the most important index for space weather and space climate: the Sunspot Number (Clette et al. 2014). In the last years, several versions of the Sunspot Number have been published (see Clette et al. 2016; Usoskin 2017) and an important effort has been made to improve the dataset of sunspot counts (Vaquero et al. 2016) and the methodologies to obtain a more accurate version of the Sunspot Number series (see, e.g. Svalgaard \& Schatten 2016; Usoskin et al. 2016; Chatzistergos et al. 2017).

In this context, recovery of historical sunspot observations is crucial to provide the best database to compute the Sunspot Number (Vaquero 2007). Although in the post-1848 period the number of records of spots is sufficient to cover each day, the number of records prior to 1848 is relatively small having serious problems for many years of the 17th and 18th centuries. In addition, from a geographical point of view, the data available generally come from European nations (Vaquero et al. 2016).

The aim of this short contribution is the recovery of two sunspot records dated in 1777. These observations appear as comments in a hand written meteorological journal of Mexico City. In fact, it is not the first time that historical observations of sunspots are reported from Mexico (Vaquero \& MorenoCorral 2008). In the following sections, we briefly describe the author and the manuscript, publish relevant information on sunspot records, and analyze their interest in the context of solar activity in the 18 th century.

\subsection{The author}

Felipe de Zúñiga y Ontiveros (FZO) was born in Oaxtepec (Mexico) in 1717 and died in Mexico City in 1793. He was married three times and had three sons (Francisco, Mariano, and Felipe). He signed his publications as "Philomatemático de la Corte y Agrimensor titulado por su majestad, de tierras, aguas y minas de todo el reino" [Philomathematician of the court and surveyor (titled by His Majesty) of lands, waters and mines of the entire kingdom]. He was a self-taught person because none of these titles were given by Mexico University. The surveyor title was inherited and Philomathematician only denoted his love for mathematics. FZO was interested in astronomy. In fact, he was the author and publisher of the Efemérides calculadas y pronosticadas según el meridiano de México [Ephemerides calculated and predicted according to the meridian of Mexico] (published since 1762). These publications were almanacs with typical astronomical prognostications of Easter dates, lunar cycles, eclipses, etc. but also weather and diseases from an astrological point of view.

FZO had a printing house. He printed mainly religious and scientific works. Among the last, he printed most of the University dissertations, scientific journals e.g. Mercurio Volante (the first medical journal of the American Continent according to López Espinosa 2000), Gazeta de Literatura de Mexico, and works of important Mexican scientists as José Antonio Alzate or Antonio de León y Gama. Therefore, FZO belongs to the Enlightenment scientific community of Mexico. Probably, the interest of FZO in sunspots was influenced by Antonio Alzate, who observed sunspots on many occasions (Vaquero 2004; Vaquero et al. 2007).

Soberón Mora (1993) published the FZO's property declaration dated in 1773. In this list, five telescopes of various sizes can be found. A small telescope stands out because its description indicated that it had a dark camera coupled to observe the spots of the Sun. In addition, also 10 filters of different colors to observe the Sun are listed. According to this declaration, it seems highly probable that FZO observed frequently sunspots because he had specific instruments to 

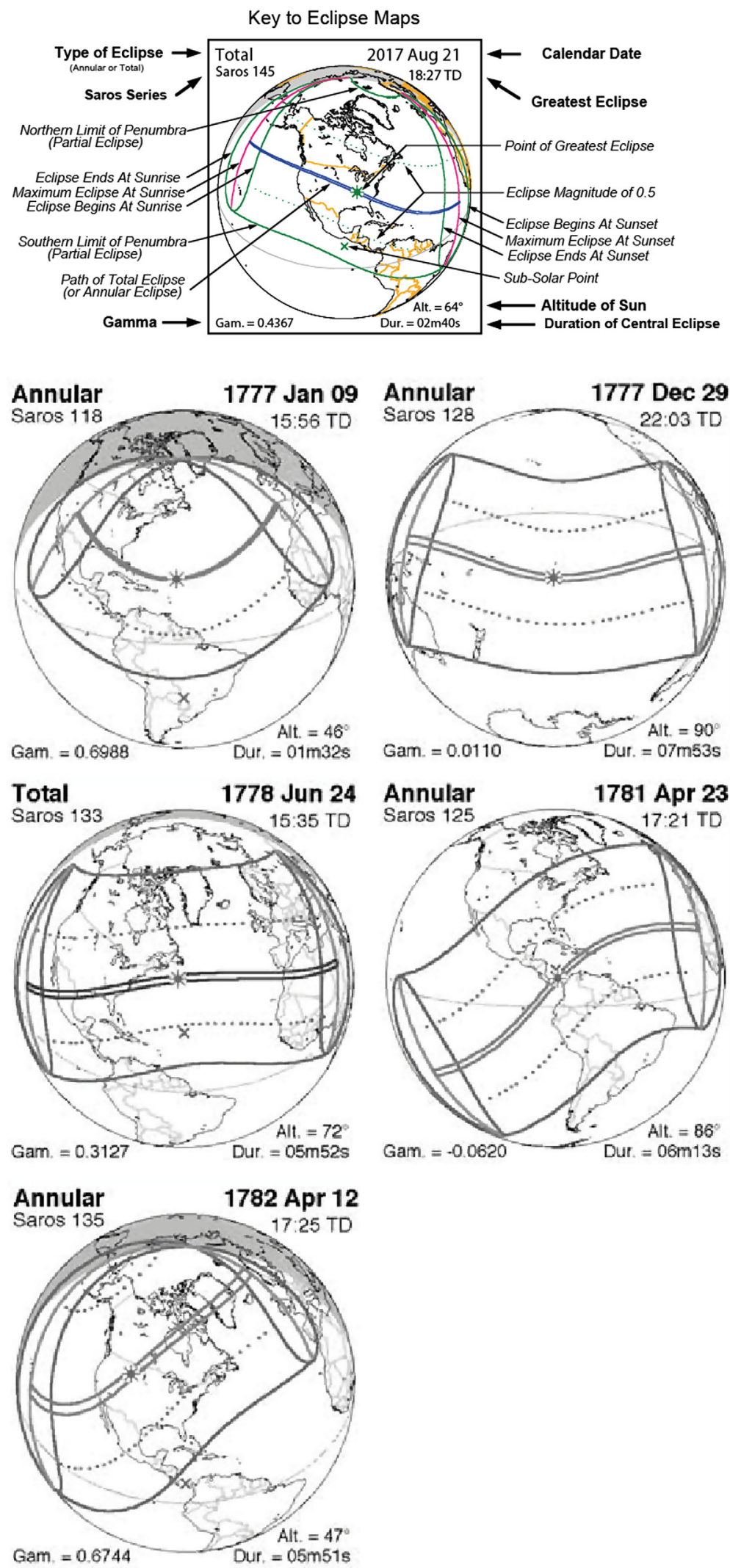

Fig. 1. Maps of the solar eclipses documented by FZO as copied from Espenak \& Meeus (2006).

do it. Unfortunately, only two observations in 1777 have been preserved in the manuscript studied here. At this time, FZO lived at Mexico City in the Jesus Street and his printing house was in La Palma Street. Probably, he performed his observations from one of these places, both in the city center.

\subsection{The manuscript}

The sunspot observations are recorded in a long manuscript (272 pages) entitled "Ephemérides astronómicas calculadas al meridiano de México, años 1775-1785" [Astronomical 


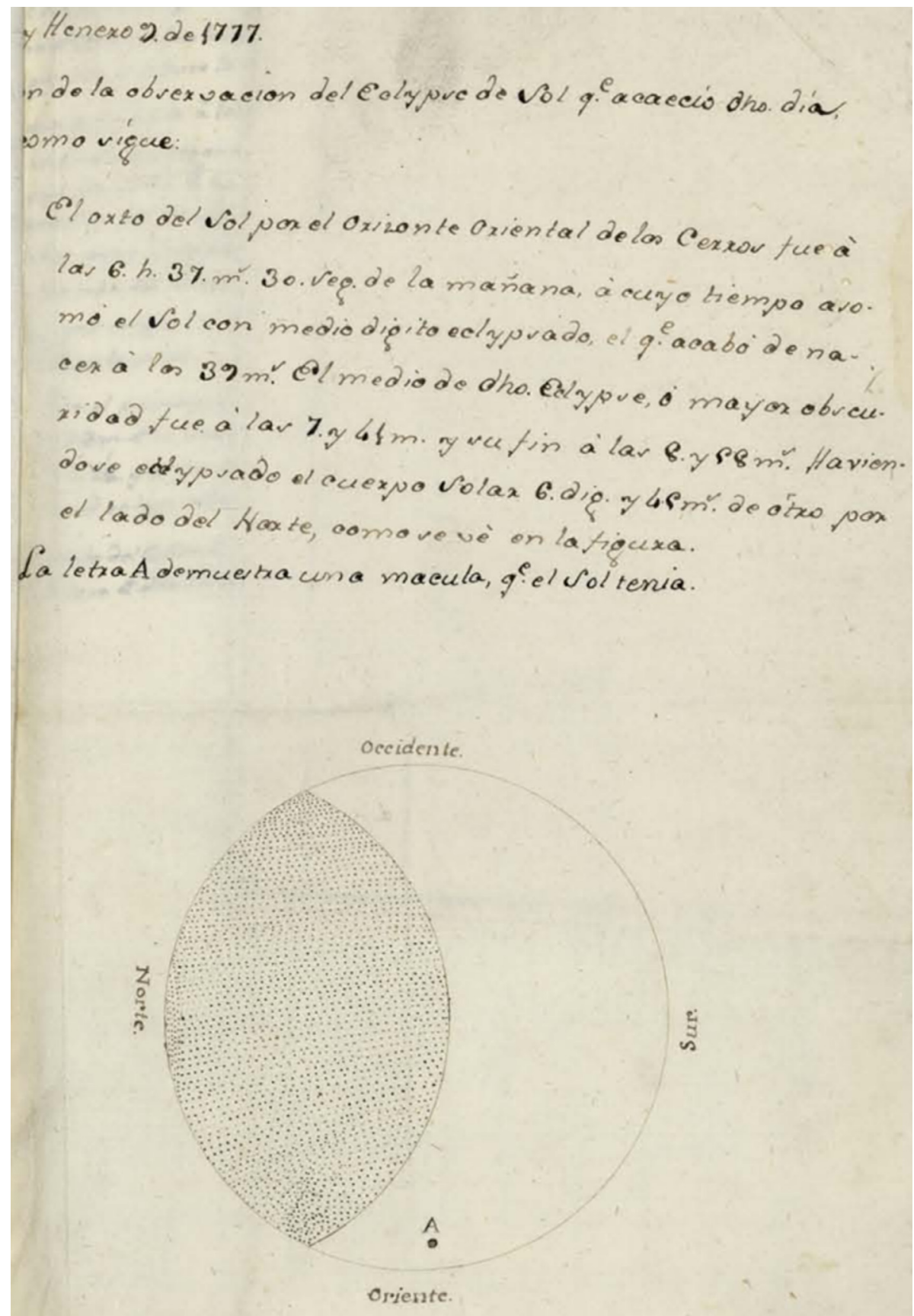

Fig. 2. Description of the solar eclipse of 9th January 1777 (courtesy of the National Library of Spain).

ephemerides calculated to the meridian of Mexico, years 1775-1785]. The manuscript is preserved in the Spanish National Library. The main objective of the manuscript is to record the astronomical ephemerides in tables of two pages per month. Moreover, a short description of the weather of each day is provided (this information is being currently studied with climatic objectives). Additionally, the manuscript is full of marginal annotations and contains intercalated pages with information of a large diversity of topics, including social, religious, personal, and scientific notes. Some examples frequently addressed are: punishment and execution of criminals by the Acordada, frequent diseases, earthquakes, how good/bad was the climate for growing fruits, processions, visits of illustrious personages, etc. Two of these annotations are sketches of the sun during the solar eclipses of the 9th January and the 29th December of 1777, in which the sunspots are represented on the solar disk. Other eclipses took place during the time of the manuscript but, unfortunately, references to sunspots were not recorded. This was the case of the following eclipses:

24th June 1778: "Este eclipse de sol no se pudo observar por la copia de nubes mui gruesas que se mantuvieron hasta las 8:25 de la mañana que abrieron una ventana y se vio el sol que aun tenía eclipsado 1.5 digito del fin, el que fue a las 8:30". [This solar eclipse cannot be observed due to the thick layer of clouds that was until 8:25 a.m. when a window was opened and the sun was seen with 1.5 digits eclipsed, the end of the eclipse was at 8:30]. About this eclipse, 

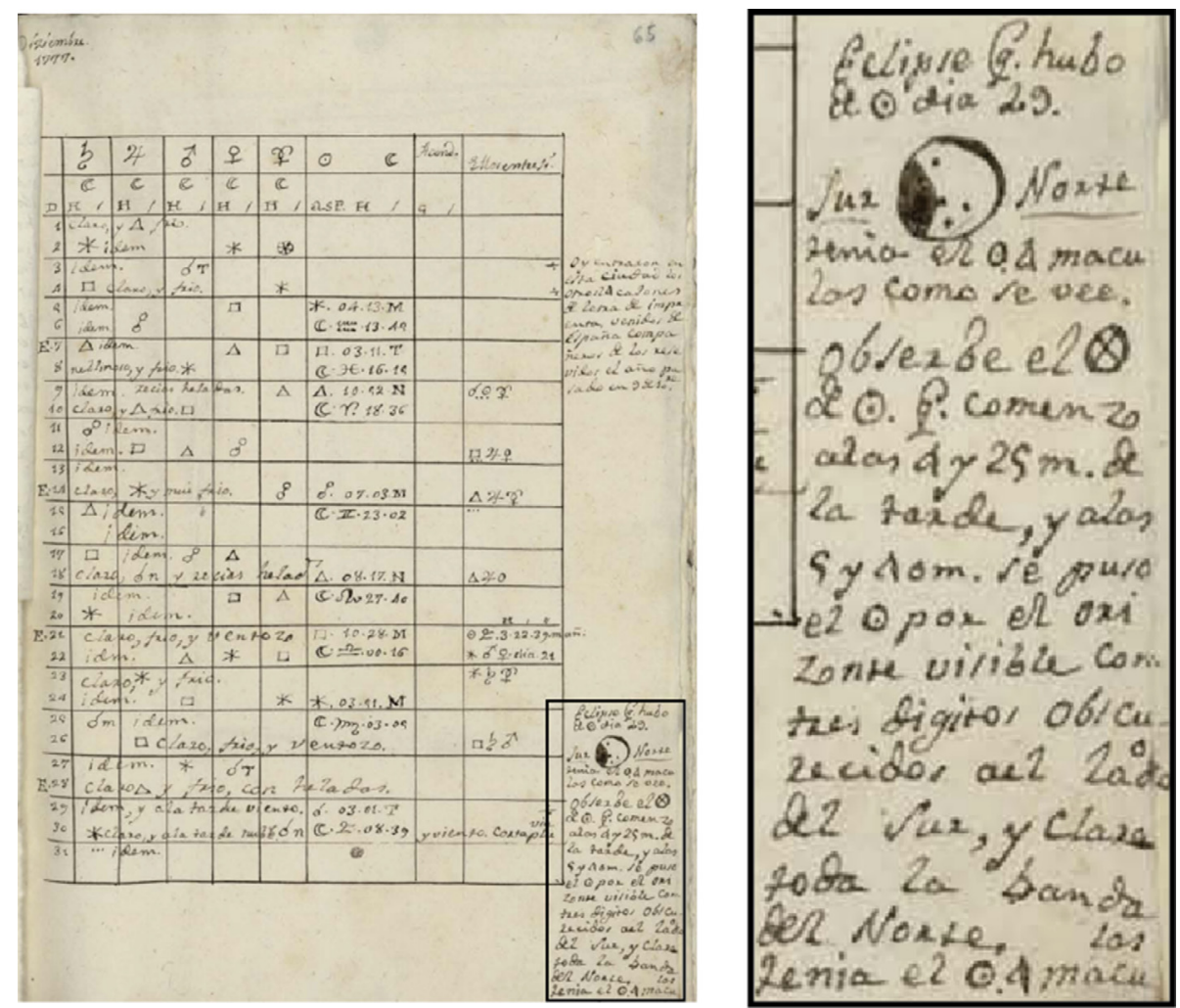

Fig. 3. Description of the solar eclipse of 29th December 1777 (courtesy of the National Library of Spain).

Antonio de León y Gama published "Orthográphica Universal del Eclipse de sol del día 24 de junio de 1778 ” edited by FZO (León y Gama 1778).

23th April 1781: "Comenzo este eclipse a las 9 y $7 \mathrm{~m}$ de la mañana y acabo a las 11 y $44 \mathrm{~m}$ fue su cantidad 3 digitos a la banda del sur". [The eclipse started at 9 and $7 \mathrm{~min}$ of the morning and finished at 11 and $44 \mathrm{~min}$. Its quantity was 3 digits in the southern part.]

12th April 1782: "Este eclipse de sol comenzo a las 8 y 31 min, medio a las $10=$ ó dio fin a las 11 y 22. Los dígitos eclipsados fuerion 9 y 3 ó al norte". [This solar eclipse started at 8 and $31 \mathrm{~min}$, mid at 10 and finished at 11 and $22 \mathrm{~min} .9$ and 3 digits were eclipsed at north.]

Note that one digit is a twelfth of the diameter of the celestial body eclipsed. Figure 1 shows the maps of all solar eclipses observed by FZO (Espenak \& Meeus 2006). This manuscript is a primary source recorded directly by FZO at the times of the events. This is an important fact, because reconstruction of sunspots is mainly based on printed sources (out of the manuscripts of important observatories that have been preserved until now), that could contain errors happened during transcription of the original source.

\section{Sunspots observations}

\subsection{9th January 1777}

In a page inserted in the manuscript (Fig. 2), FZO described the solar eclipse of 9th January of 1777 as follows:

"Henero 9 de 1777. de la observacion del eclipse de sol que acaeció dicho día como sigue:
El orto del Sol por el orizonte oriental de los cerros fue á las 6 h 37 min 30 seg de la mañana a cuyo tiempo asomó el sol con medio digito eclipsado el que acabo de nacer a los 39 min. El medio de dicho Eclypse o mayor obscuridad fue a las 7 y $41 \mathrm{~min}$ y su fin a las 8 y $58 \mathrm{~min}$. Haviendose eclipsado el cuerpo solar 6 dig. y $45 \mathrm{~m}$ de otro por el lado del Norte, como se ve en la figura.

La letra A demuestra una macula que el sol tenia".

[9 January 1777. On the observation of the solar eclipse that happened that day as follows:

The sunrise on the eastern horizon of the hills was at $6 \mathrm{~h}$ $37 \mathrm{~min} 30 \mathrm{sec}$, at which time the sun was eclipsed with half digit, the sunrise was completed at $39 \mathrm{~min}$. The mean or the greatest obscurity of the said eclipse was at 7 and $41 \mathrm{~min}$ and ended at 8 and $58 \mathrm{~min}$. Eclipsing of the solar body was 6 dig and $45 \mathrm{~min}$ from the northern side, as seen in the figure.

The letter A shows a sunspot that the sun had.]

The sunspot registered by FZO was located close to the eastern limb and close to the equator of the sun. The unique observer in January of 1777, according to Hoyt \& Schatten (1998), was Erasmus Lievog. He observed from the observatory of the Copenhagen University, an institution with a long tradition in sunspot observations at this time. He observed 11 days during January 1777 and the 9th recorded one group in the solar disk in agreement with FZO.

\subsection{9th December 1777}

In a marginal note in the page corresponding to December 1777, FZO drew a sketch of the solar disk during the eclipse 
(a)

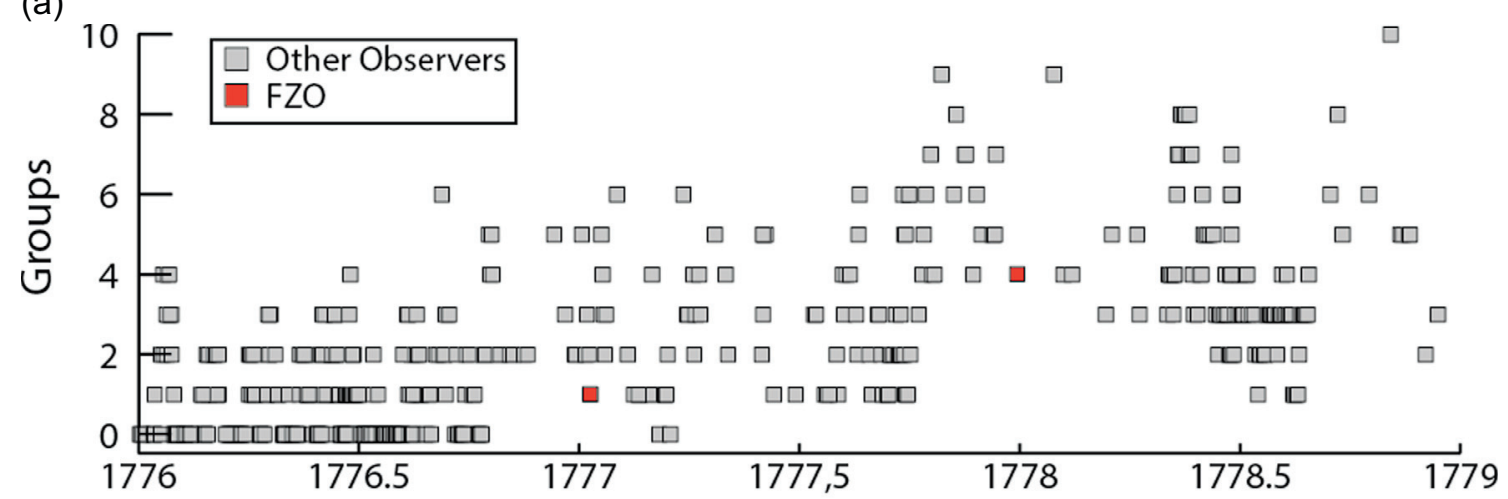

(b)

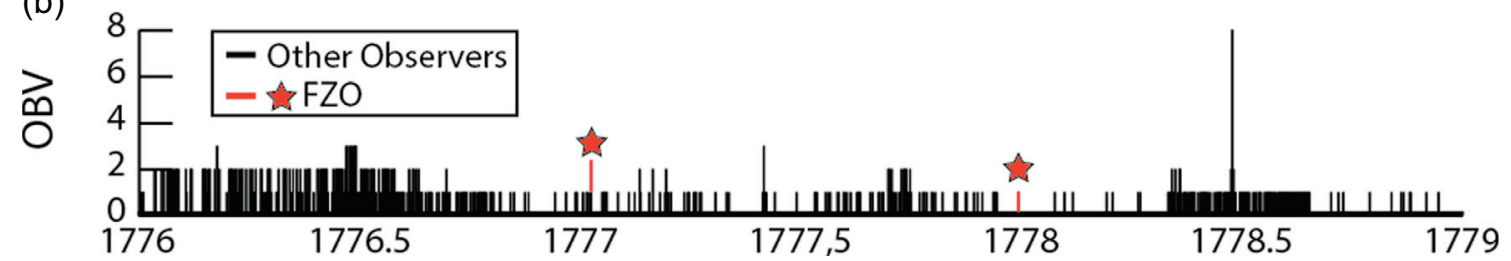

Fig. 4. Number of sunspot groups observed (a) and number of observations per day (b) from 1776 to 1778 (Vaquero et al. 2016). In both panels, observations by FZO have been highlighted in red.

of 29th December 1777 (Fig. 3) complemented with a short description:

\begin{abstract}
“Eclipse que hubo el día 29. Tenia el sol 4 maculas como se vee. Observe el eclipse de sol que comenzó a las 9 y 25 min de la tarde, a las 9 y 40 min se puso el sol por el orizonte visible con tres dígitos obscurecidos del lado del sur, y clara toda la banda del Norte, las tenia el sol 4 maculas como se vee arriba" [Eclipse that there was the day 29. The sun had 4 sunspots as represented. I observed the eclipse of sun that began at 9 and $25 \mathrm{~min}$ in the afternoon, at 9 and $40 \mathrm{~min}$ the sun set for the visible horizon with three digits obscured from the south side, and clear the whole of the north, the sun had 4 sunspots as seen above.]
\end{abstract}

Four sunspot groups were recorded: three of them appear close to the solar equator, the other a little bit to the north. According to Hoyt \& Schatten (1998), nobody else made observations during this day and only four days of observations were recorded during December 1777: seven groups were observed during days 8,9 , and 10 by Thomas Bugge in Copenhagen (Vaquero et al. 2016), and five groups were recorded during the day 11 by Johann Casper Staudacher in Nuremberg (Arlt 2008; Svalgaard 2017).

\section{Data context}

Figure 4 shows the number of groups observed by all the observers registered by Vaquero et al. (2016) and the number of observations per day from 1776 to 1778 . The observations by FZO have been highlighted in red. There are 17 observers during this period, with Erasmus Lievog being the observer with the greatest number of observational days (196 in total). On the other hand, six observers only recorded one observation during these years. The observations were more frequent during 1776. In fact, the years $1777-1795$ form one of the periods with low frequency of observations in the entire record
(Vaquero et al. 2016) due to the drop of interest in solar monitoring by major astronomical observatories during that epoch. Indeed, the FZO's observation of 29th December 1777 was in a period of 47 days without observations (from the 11th December 1777 to 28th January 1778). The 24th June 1778 is the most observed day ( 8 different records in total) during this period. This is because a solar eclipse occurred in Europe (Fig. 1). There are many observations performed during solar eclipses or planetary transits, so these dates are interesting to search for new sunspot observations especially when these events were not visible in Europe.

\section{Conclusion}

In this short contribution, we have revealed two sunspot records made by FZO in the year 1777 during observations of solar eclipses (9th January and 29th December). Although we only found two observations made by FZO, these observations are important due to the small number of observations in these years collected so far in the databases. FZO observations are compatible with our current knowledge of solar activity during these years, during the rise phase of the solar cycle 3 , the largest cycle during the 18 th century.

Acknowledgements. Supports from the Junta de Extremadura (Research Group Grant GR15137) and from the Ministerio de Economía y Competitividad of the Spanish Government (AYA2014-57556-P) are gratefully acknowledged. FDC thanks the support from the EU and Spanish Ministry of Economy and Competitiveness for funding, in the frame of the collaborative international consortium IMDROFLOOD financed under the ERA-NET Cofund WaterWorks2014. The editor thanks Ilya Usoskin and an anonymous referee for their assistance in evaluating this paper.

\section{References}

Arlt, R. Digitization of sunspot drawings by Staudacher in 1749-1796. Sol. Phys., 247, 399-410, 2008.

Chatzistergos, T., I.G. Usoskin, G.A. Kovaltsov, N.A. Krivova, and S.K. Solanki. New reconstruction of the sunspot group number 
since 1739 using direct calibration and backbone methods. $A \& A$, 2017, DOI: 10.1051/0004-6361/201630045.

Clette, F., L. Svalgaard, J.M. Vaquero, and E.W. Cliver. Revisiting the sunspot number. Space Sci. Rev., 186, 35-103, 2014, DOI: $10.1007 / \mathrm{s} 11214-014-0074-2$.

Clette, F., E.W. Cliver, L. Lefèvre, L. Svalgaard, J.M. Vaquero, and J.W. Leibacher. Preface to topical issue: recalibration of the sunspot number. Sol. Phys., 291, 2479-2486, 2016, DOI: $10.1007 / \mathrm{s} 11207-016-1017-8$.

Espenak, F., and J. Meeus. Five millennium canon of solar eclipses: -1999 to +3000, NASA TP-2006-214141, Maryland, NASA Center for AeroSpace Information, 2006.

Hoyt, D.V., and K.H. Schatten. Group sunspot numbers: a new solar activity reconstruction. Sol. Phys., 179, 189-219, 1998.

León y Gama, A Descripción orthographica universal del eclipse de sol del día 24 de Junio de 1778, Mexico, Imprenta nueva Matritense de D. Felipe de Zúñiga y Ontiveros, 1778.

López Espinosa, J.A. La primera revista médica de América. ACIMED, 8(2), 133-139, 2000.

Owens, B. Slow science. Nature, 495, 300-303, 2013.

Soberón Mora, A. Felipe de Zúñiga y Ontiveros, un impresor ilustrado en la Nueva España. TEMPUS, 1, 51-75, 1993.

Svalgaard, L., and K.H. Schatten. Reconstruction of the sunspot group number: the backbone method. Sol. Phys., 291, 2653-2684, 2016, DOI: 10.1007/s11207-015-0815-8.
Svalgaard, L.A. Recount of sunspot groups on Staudach's drawings. Sol. Phys., 292, 4, 2017, DOI: $10.1007 / \mathrm{s} 11207-016-1023-\mathrm{x}$.

Usoskin, I.G. A history of solar activity over millennia. Living Rev. Sol. Phys., 14(3), 1-97, 2017.

Usoskin, I.G., G.A. Kovaltsov, M. Lockwood, K. Mursula, M. Owens, and S.K. Solanki. A new calibrated sunspot group series since 1749: statistics of active day fractions. Sol. Phys., 291, 2685-2708, 2016, DOI: 10.1007/s11207-015-0838-1.

Vaquero, J.M. On the solar activity during the year 1784. Sol. Phys., 219, 379-384, 2004.

Vaquero, J.M. Historical sunspot observations: A review. Adv. Space Res., 40(7), 929-941, 2007.

Vaquero, J.M., and M.A. Moreno-Corral. Historical sunspot records from Mexico. Geofis. Int., 47, 189-192, 2008.

Vaquero, J.M., R.M. Trigo, M.C. Gallego, and M.A. Moreno Corral. Two early sunspots observers: Teodoro de Almeida and José Antonio Alzate. Sol. Phys., 240, 165-175, 2007.

Vaquero, J.M., L. Svalgaard, V.M.S. Carrasco, F. Clette, L. Lefèvre, M.C. Gallego, R. Arlt, A.J.P. Aparicio, J.G. Richard, and R. Howe. A revised collection of sunspot group numbers, Sol. Phys., 291, 3061-3074, 2016, DOI: $10.1007 / \mathrm{s} 11207-016-0982-2$

Cite this article as: Domínguez-Castro F, Gallego MC \& Vaquero JM. Sunspots sketches during the solar eclipses of 9th January and 29th December of 1777 in Mexico. J. Space Weather Space Clim., 7, A15, 2017, DOI: 10.1051/swsc/2017012. 